\title{
The Report on Endemism of Liver Cancer in Indian Subcontinent-A Reterospective Study
}

\author{
Gunasekaran Vetrichelvi ${ }^{1}$, Kannan Elangovan², S. Niranjali Devaraj ${ }^{3}$ \\ ${ }^{1,3}$ Department of Biochemistry, University of Madras , Guindy Campus, Chennai-600025, Tamilnadu, India \\ ${ }^{2}$ CAS in botany , University of Madras , Guindy Campus, Chennai-600025, Tamilnadu, India
}

\begin{abstract}
Indian survey on HCC incidence and mortality is scanty. the Indian Council of Medical Research (ICMR) is the National cancer registry program, recently expanded to include 21 population based and 6 hospital based cancer registries to study the prevalence of cancers in various geographical regions within the country. This study is mainly based on the data's published by ICMR available in the cancer registry website (www.ncrpindia.org) in 2008 . The other source of information were from International Agency for Research on Cancer (WHO) report. These available data reports for the age adjusted incidence rate for men with hepatocellular carcinoma (HCC) ranges from 0.7 to 7.5 and for women 0.2 to 2.2 per 100,000 population per year in India. The gender specific incidence rate is about male: female ratio is 4:1. The age of patients admitted with HCC varies from 40 to 70 years. the age standardized mortality rate for men is $6.8 / 100,000$ and for women is 5.1/100,000 for HCC in India.. The unpublished data's suggest that the incidence of HCC is increasing in India with the need for proper registry to manage the disease burden in this country.
\end{abstract}

Keywords: HCC, Epidemiology, India, endemic,m HBV and HCV prevalence

Abbreviations: AAIR, age adjusted incidence rate; ASMR, age standardized mortality rate; HCC, hepatocellular carcinoma; IARC, international agency for cancer research; ICMR, Indian Council of Medical Research.

\section{Introduction}

Liver cancer, the fifth most common cause of cancer and the third most common cause of cancer related mortality worldwide[1] , Hepatocellular carcinoma (HCC) is a global leading cause of cancer-related death , accounting for $90 \%$ of primary liver cancer[2] , and the burden of this devastating cancer as a sequel of cirrhosis is expected to increase further in coming years. Because HCC been the predominant primary liver cancer in most countries, the global variations in rates of liver cancer discussed below can be considered as a broadly accurate reflection of trends in HCC incidence[3].

Various epidemiologic studies revealed the complex etiological factors related molecular pathogenesis of HCC[4]. Epidemiological analysis of HCC data is important in standardizing the management strategies against disease progression. Hepatitis B and C infections were the most common factors reported to cause HCC in various regions[5] Although previous studies have contributed considerably to the knowledge of HCC epidemiology, with diverse patient populations, there are limitations associated with the currently available data.

\section{Liver Cancer Burden In Fifteen Asian Countries and United States With Special Attention on India - A Comparative Study}

India and China, together attribute for $37 \%$ of the worldwide population . in addition these countries were also reported with 3 million of newly diagnosed cancer cases every year . Three fourths of new worldwide liver cancer cases in males and two thirds in females occur in the fifteen Asian countries such as Japan, South, East, Southeast Asia , Taiwan, South Korea , Singapore, , Malaysia, China, Philippines, Thailand, Mongolia , Sri Lanka, Vietnam, Indonesia, , India, Laos, and
Cambodia, with China alone contributes more than half of the world's newly diagnosed liver cancer cases. in comparison with china ,less than $4 \%$ of the liver cancer cases occur in the United States.Analyses in this report is based on the available data describing liver cancer incidence, prevalence, and mortality rate maintained by the International Agency for Researchon Cancer (IARC). The quality of the data varies by country based on the accuracy of the regionally available data.

\section{Incidence Rate of Liver Cancer in Asia}

In Asia , India accounts for the country with lowest cancer incidence rates in males (99 per 100,000 males), Among the $9,48,858$ total number of cancer cases ( based on national cancer registry program (NCRP) ) registered in India , excluding non melanoma skin cancer, only 20,144 cases (both sexes) contributed to liver cancer, highlights its non availablityin any states leading cancers in India comparatively to the other Asian subcontinents, the mean incidence of liver cancer in four population-based registries is $2.77 \%$ for males and $1.38 \%$ for females. The prevalence of liver cancer in India varies from $0.2 \%$ to $1.6 \%$ by 2008 , Hepatitis B virus (HBV) infection is the most prevalent etiologic factor in high incidence areas, while hepatitis $\mathrm{C}$ (HCV) infection is the most common in the low incidence areas [6][7]

Incidence Rate of Liver Cancer In Asia 


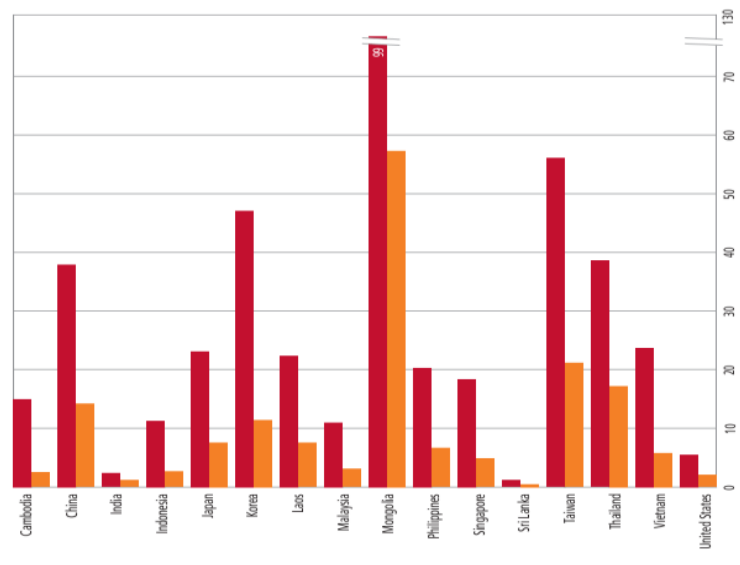

Rate per 100,000

Igestandandized b tre Word Stantard Popilation.

Males

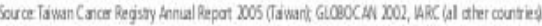

Unlike other low incidence zone, in India HBV is the main etiological factor associated with liver cancer [8][9][10] In the west, majority of liver cancer are diagnosed incidentally during routine evaluation. However, in India, most of the patients were ruled out of curative treatments in clinical practice due to their enrollment at an advanced stages. India is in a low incidence zone for liver cancer. In our country, paucity in the published literature on profile of liver cancer patients making the formulation of a proper health care strategy difficult[11]. Yet only some Comprehensive analysis have been done on patients especially with regard to their clinical, etiological, radiological and cytohistological profile . Clinical research revealed that , in India , maximum incidence of liver cancer occurs in the fifth to sixth decade of man's life where the HCV-related HCC occurs in older age group as compared to HBV-related HCC[12]. The male preponderance is similar in many studies .The populationbased data shows a male to female ratio of 4:1 [13]. However, high preponderance of HCC in males reported in hospital-based data could suggest a gender bias in seeking medical treatment

\section{Mortality Rate of Liver Cancer In Asia}

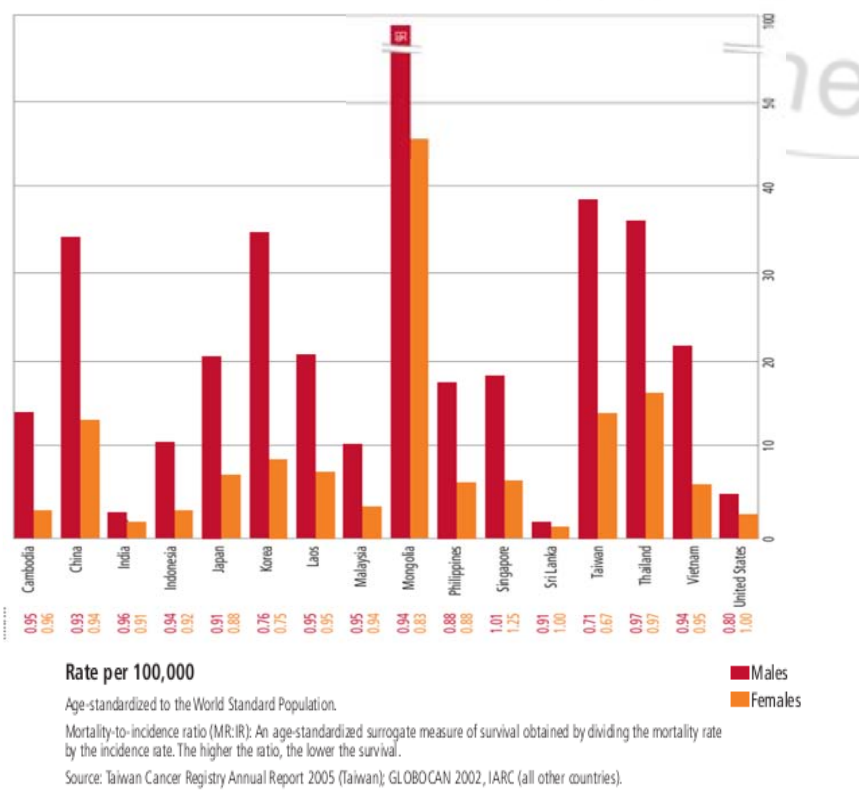

Population statistics are based on data from the United States Census BureauInternational Data Base (IDB), 2008.
All age-standardized rates in the report usethe World Health Organization (WHO) World Standard Population

\section{Etiology in India}

\section{Hepatitis B}

Hepatitis B virus (HBV) is one of the major health problem Worldwide[14] . India is in intermediate HBV endemic zone due to theprevalence of $\mathrm{HBsAg}$ ranging from $2 \%$ to $8 \%$ among general population . According to the IARC \& ICMR registry, number of $\mathrm{HBV}$ carriers is estimated to be 50 million in 2010 that forms the second largest pool of chronic HBV infections contributing to nearly $15 \%$ of the entire pool of HBV carriers in the world the incidence of HCC was found to be very much lower in comparison to the neighboring countries of East Asia. An age standardized HCC incidence rate (ASR) of 5.3 and relative frequency of $4.8 \%$ was reported in males. However among the women, relative frequency of $3.1 \%$ and ASR of 3.9 was documented. More-over, a recent study found the incidence of HCC in India to be low enough and excluded liver from the list of high-risk cancer site among Indians [21]

India comprises of multiracial communities with wide variations in ethnicity and cultural patterns, which is attributable to its geographical location, gene influx , due to invasion and/or anthropological migrations in the past. Moreover, epidemiology of $\mathrm{HBV}$ is also influenced by the recent increase in trade, trafficking and use of illicit drugs in the eastern and north eastern parts of India. However, data on the molecular epidemiology of HBV in India is scanty. HBV genotypes $\mathrm{A}$ and $\mathrm{D}$ have been well documented from different parts of mainland India. Interestingly, in addition to genotypes $\mathrm{A}$ and $\mathrm{D}$, genotype $\mathrm{C}$ having high nucleotide similarity with south East Asian subgenotype Cs/C1 strain, have been detected exclusively from eastern Indian HBV carriers, suggesting a recent introduction [15][16]

\section{Hepatitis C}

This infection impact in the Indian society, mainly due to the shortcomings in the India's blood-banking system[17], alarmingly the two studies specifically looking at the professional donors have noted a prevalence of $55.3 \%$ and $87.3 \%$ [16]. This highlights the need for more stringent screening of blood donors in India. Only some populationbased studies have been reported from various regions in the country regarding the prevalence of $\mathrm{HCV}$ in India. The maximal prevalence was in the older age group $>60$ years $(1.5 \%)$ as opposed to the lowest prevalence in the age group $<10$ years $(0.31 \%)$. hepatitis acts as an important human carcinogen for liver cancer in india excluding other etiological factors such as aflatoxin[18], tobacco smoking ,dietary factors , obesity and diabetes, oral contraceptives and iron overload[2].

\section{Discussion}

There are no conclusive evidences on actual prevalence of Hepatitis B in India. Meta -analysis in Indian continent estimates $2.1 \%$ prevalence and $1.7 \%$ carrier rates . Jaundice states for almost $1 \%$ of deaths preliminary to chronic liver cancer $(0.76 \%)$ due to both Hepatitis B\&C infections. Yet no Indian pilot studies generate statistics on virus related 


\section{International Journal of Science and Research (IJSR) \\ ISSN (Online): 2319-7064 \\ Index Copernicus Value (2013): 6.14 | Impact Factor (2015): 6.391}

hepatocellular carcinogenesis in India. Cirrhosis remains the major etiologial factor for hepatocellular carcinogenesis, Data's on patients reported with cirrhosis and their respective mortality rate has not been demonstrated yet in Indian patient registry. ICMR reports that about 10000 persons die of HCC due to Hepatitis B every year, contradictory to the progression rates from Hepatitis B for Taiwan where 1 in 4 male carriers die of the disease.

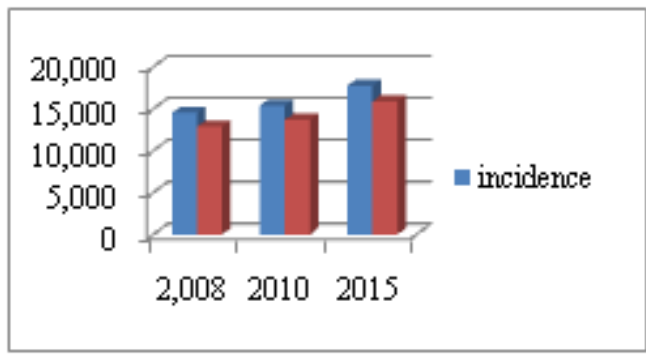

Liver Cancer in India male

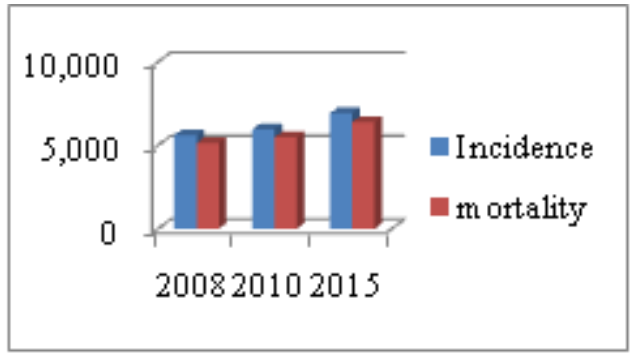

Liver Cancer in India Female

2015 liver cancer incidence and mortality rate is based on the statistical data's available on the GLOBOCAN international database

The projected cases of HCC from ICMR cancer registry in 2009 was 22238 cases. These are likely under estimates as the most common presentation of this cancer is with complications or sequel of cirrhosis liver and thus may be missed from routine reporting of cancer from pathology, radiotherapy and radiology departments. There are 8 genotypes of $\mathrm{HBV}$. The HBV genotypes prevalent in India are D in $60-70 \%, \mathrm{~A}-20-30 \%$ and C approximately 5\% (mainly from East India).Studies have shown that $\mathrm{D}$ genotype is associated with increased perinatal transmission. However, there are some other studies which have not shown this association In patients with liver disease $\mathrm{HBs} \mathrm{Ag}$ positivity is seen in $12.5-21 \%$ of Acute viral hepatitis, 11 $27 \%$ of acute liver failure, $40 \%$ of sub acute hepatic failure , $40-60 \%$ of chronic liver disease and $60-80 \%$ of hepatocellular carcinoma. A study on HBV disease profile based on liver biopsy of consecutive patients who were HbsAg positive presenting to AIIMS from Jan. 2008 to June 2009 , showed that $80 \%$ are silent infections. $44 \%$ of the patients were asymptomatic healthy carriers, $13 \%$ were immunotolerant, 28\% were HBeAg positive chronic hepatitis 7 and 15\% were HBeAg negative chronic hepatitis. Based on the natural course of the HBV infection and the disease profile at presentation and considering an HBV carrier rate of $2 \%$, the annual frequency of cirrhosis will be 3 lakhs and HCC will be 21000 .

\section{References}

[1] K. a. McGlynn, W.T. London, The Global Epidemiology of Hepatocellular Carcinoma: Present and Future, Clin. Liver Dis. 15 (2011) 223-243. doi:10.1016/j.cld.2011.03.006.

[2] D.D. Esposti, M. Soffritti, A. Lemoine, E. Tibaldi, M. Manservigi, H.P. Brousse, et al., Hepatocellular Carcinoma : Epidemiology and Etiology, (2010).

[3] T.Y.-M. Leong, A.S.-Y. Leong, Epidemiology and carcinogenesis of hepatocellular carcinoma., HPB (Oxford). 7 (2005) 5-15. doi:10.1080/13651820410024021.

[4] A. Patel, Molecular Targeted Therapy in Hepatocellular Carcinoma: From Biology to Clinical Practice and Future, (2014). doi:10.1007/s11864-014-0291-7.

[5] A.J. Sanyal, S.K. Yoon, R. Lencioni, The etiology of hepatocellular carcinoma and consequences for treatment., Oncologist. 15 Suppl 4 (2010) 14-22. doi:10.1634/theoncologist.2010-S4-14.

[6] J.M. Llovet, Updated treatment approach to hepatocellular carcinoma, J. Gastroenterol. 40 (2005) 225-235. doi:10.1007/s00535-005-1566-3.

[7] P.P. and J.F. D. Maxwell PARKIN*, Estimates of the Worldwide Incidence of 25 Major Cancers in 1990, Int. J. Cancer. 80 (1999) 827-841.

[8] G. Ai, K. Sa, T. Mb, I. Waked, T.R. Sd, Hepatocellular carcinoma : epidemiology, risk factors and pathogenesis . PubMed Commons, 14 (2016) 18666317.

[9] A.M. Di Bisceglie, Epidemiology and Clinical Presentation of Hepatocellular Carcinoma, J. Vasc. Interv. Radiol. $13 \quad$ (2002) S169-S171. doi:10.1016/S1051-0443(07)61783-7.

[10] T.M. Block, A.S. Mehta, C.J. Fimmel, R. Jordan, Molecular viral oncology of hepatocellular carcinoma., Oncogene. 22 (2003) 5093-107. doi:10.1038/sj.onc.1206557.

[11] A. Overview, Prevention of Hepatitis B in India, World Heal. Organ. 141 (2002) 1-76.

[12] N. Shinkai, Y. Tanaka, K. Ito, M. Mukaide, I. Hasegawa, Y. Asahina, et al., Influence of hepatitis B virus $\mathrm{X}$ and core promoter mutations on hepatocellular carcinoma among patients infected with subgenotype C2, J. Clin. Microbiol. 45 (2007) 3191-3197. doi:10.1128/JCM.00411-07.

[13] A. Nandakumar, P.C. Gupta, P. Gangadharan, R.N. Visweswara, D.M. Parkin, Geographic pathology revisited: Development of an atlas of cancer in India, Int. J. Cancer. $116 \quad$ (2005) 740-754. doi:10.1002/ijc.21109.

[14] V.E. Gurtsevitch, Human oncogenic viruses: hepatitis B and hepatitis $\mathrm{C}$ viruses and their role in hepatocarcinogenesis., Biochemistry. (Mosc). 73 (2008) 504-513. doi:10.1134/S0006297908050039.

[15]L.B. Seeff, J.H. Hoofnagle, Epidemiology of hepatocellular carcinoma in areas of low hepatitis B and hepatitis C endemicity., Oncogene. 25 (2006) 37713777. doi:10.1038/sj.onc.1209560.

[16] S.K. Acharya, Epidemiology of Hepatocellular Carcinoma in India, J. Clin. Exp. Hepatol. 4 (2014) S27-S33. doi:10.1016/j.jceh.2014.05.013.

[17] S. Mukherjee, K. Dhar, S. Datta, A.K. Mukherjee, Hepatocellular carcinoma in eastern India , a detail 


\section{International Journal of Science and Research (IJSR) \\ ISSN (Online): 2319-7064}

Index Copernicus Value (2013): 6.14 | Impact Factor (2015): 6.391

analytical report from a tertiary care hospital, 1 (2015) 69-73.

[18] M. Abdel-Wahab, M. Mostafa, M. Sabry, M. El-Farrash,

T. Yousef, Aflatoxins as a risk factor for hepatocellular carcinoma in Egypt, Mansoura Gastroenterology Center Study, Hepatogastroenterology. 55 (2008) 1754-1759. 